\section{Policy Research W
The Real Impact of Financial Shocks}

\section{Evidence from the Republic of Korea}

\section{Ilker Domaç}

Giovanni Ferri
WPS 2010

2010

\author{
To what extent did tighterling \\ monetary policy magnify the \\ East Asian crisis through its \\ adverse effects on credit \\ supply? \\ In the Republic of Korea, \\ interest rate spreads, which \\ capture credit channel effects, \\ influence economic activity, \\ and these effects are \\ disproportionately larger for \\ small and medium-size \\ enterprises. So policymakers \\ who neglect credit channel \\ effects might be "overkilling \\ the economy" and altogether \\ overlooking the \\ disproportionate effects of \\ monetary and financial shocks \\ on some sectors.
}

The World Bank

East Asia and Pacific Region

Poverty Reduction and Economic Management Sector Unit and

Financial Sector Development Sector Unit

November 1998 
Policy Research Working Paper 2010

\section{Summary findings}

The debates surrounding the recent East Asian crisis have focused not only on causes but also on policy actions in the wake of the initial shock. This has raised questions about the relationship between monetary policy and market confidence. Specifically, would rising interest rates bolster or depress market confidence? To answer this question requires assessing whether, and to what extent, monetary and financial shocks are magnified through the economy via the credit channel.

Domaç and Ferri focus on the Republic of Korea - a particularly good case for testing credit channel effects - with two objectives:

- To ascertain whether and to what extent interest rate spreads could help predict subsequent fluctuations in real economic activity.
- To test whether small and medium-size enterprises suffer more than other businesses do from the adverse effects of the credit channel.

The authors'empirical findings support the hypothesis that spreads that capture credit channel effects do indeed influence economic activity. Specifically, spreads contain significant information for predicting the future course of industrial production. The effect is, as one might have assumed, disproportionately larger for small and medium-size enterprises. Thus policymakers, in Korea and elsewhere, who neglect credit channel effects might be "overkilling the economy" and altogether overlooking the disproportionate effects of monetary and financial shocks on various segments of the economy.

This paper - a product of the Poverty Reduction and Economic Management Sector Unit and the Financial Sector Development Sector Unit, East Asia and Pacific Region - is part of a larger effort in the region to analyze the patterns and consequences of the East Asian crisis, with particular reference to the link between the real and financial sectors. Copies of the paper are available free from the World Bank, $1818 \mathrm{H}$ Street NW, Washington, DC 20433. Please contact Muriel Greaves, room MC8-150, telephone 202-458-1876, fax 202-522-1784, Internet address mgreaves@worldbank.org. The authors may be contacted at idomac@worldbank.org or gferri@worldbank.org. November 1998. (32 pages)

The Policy Research Working Paper Series disseminates the findings of work in progress to encourage the exchange of ideas about development issues. An objective of the series is to get the findings out quickly, even if the presentations are less than fully polished. The papers carry the names of the authors and should be cited accordingly. The findings, interpretations, and conclusions expressed in this paper are entirely those of the authors. They do not necessarily represent the view of the World Bank, its Executive Directors, or the countries they represent. 


\title{
The Real Impact of Financial Shocks: Evidence from Korea
}

by

\author{
Ilker Domaç and Giovanni Ferri*
}

* Ilker Domaç and Giovanni Ferri are economist and principal financial economist in the East Asia Pacific Region, respectively. 



\section{INTRODUCTION}

The East Asian crisis has stimulated an intensive debate, not only on the causes, but on the policy actions that have been adopted in response to the initial shock. The question perhaps at the center of the most vehement dispute is: to what extent can tight monetary policy help restore market confidence? Many economists have acknowledged that monetary restriction was necessary to achieve stabilization in the crisis countries. Some, however, have argued that under the prevailing circumstances, rising real interest rates might fail to bolster market confidence and thus prove counter-productive.' Indeed, some features of the East Asian economies, i.e. bank-based financial systems and high leverage, appear particularly conducive to a significant credit channel of transmission of monetary/financial shocks. The magnifying effects stemming from this channel render these economies particularly vulnerable to monetary/financial shocks.

While some have already provided preliminary evidence that credit channel effects may have triggered a credit crunch in East Asia, ${ }^{2}$ relatively little work has been done trying to assess the magnitude of the impact. In this paper, we focus on South Korea (henceforth Korea) in an attempt to perform such an assessment. We focus on Korea mainly for three reasons. First, Korea is the most developed among the five East Asian crisis countries, namely, Indonesia, Korea, Malaysia, the Philippines, and Thailand. Among these countries, Korea probably enjoys the most developed financial

1 For instance. Feldstein (1998) claims that high real interest rates caused more harm than good by leading to widespread bankruptcies. thus undermining the prospect of loan repayment.

2 See. for example. Ding. Domaç. and Ferri (1998). 
markets where corporations can issue sizable amounts of both bonds and commercial paper. As such, were we to find strong lending channel effects for Korea, there would be a strong presupposition that analogous effects could possibly apply to the other crisis countries. Second, the intensity of monetary restriction in Korea was by most measures the highest, thus making it the best candidate to identify the propagation of the monetary shock through the credit channel. Third, some of the relevant data necessary to test our hypotheses were promptly available for Korea but not for the other crisis countries.

Analyzing the relationship between some specific interest rate spreads capturing credit channel effects and industrial production constitutes the crux of our investigation. More specifically, we perform various statistical tests to assess the direction of causality between the spreads and industrial production. We also make an attempt to quantify the impact of the credit channel variables on industrial production. Furthermore, we test the commonly held hypothesis that small and medium-sized enterprises (SMEs) suffer disproportionately from the adverse consequences of the credit channel. To this end, we contrast the results obtained for the overall index of industrial production with those obtained for the index of industrial production of SMEs.

The empirical results underscore that causality clearly runs from the spreads capturing credit channel effects to production; the causality is stronger for SMEs' production than it is for overall production. Regarding the size of the impact, we find that a 1 percentage point increase in the spread between bank lending rate and Government bond rate is associated with a decline of 1.4 percent in overall industrial production and a decline of 1.7 percent in SMEs' industrial production. Considering that this spread has increased by at least 5 percentage points after the initial shock and the 
inception of the restrictive monetary policy, this could imply a drop of around 7 percent for overall industrial production and somewhere between 8 and 9 percent for SMEs' industrial production.

The rest of the paper is organized as follows. Section 2 presents a non-technical exposition of our approach to identify credit channel effects. Section 3 briefly describes the developments leading to a credit crunch in the aftermath of the crisis in Korea. Section 4 presents the empirical framework and the results. Section 5 concludes the paper.

\section{A NON-TECHNICAL EXPOSITION OF THE APPROACH}

\subsection{The Framework}

Our approach is inspired by the method that we find most convincing, namely, relying on the spread between bank lending rates and a set of market interest rates on various other risk-free and risk-bearing assets. The conjecture we follow is rather simple (see Bernanke and Blinder, 1988). A decline in either bank loans or a decline in their growth following a monetary tightening is not sufficient to pin down an adverse movement in banks' loan supply. This is because the decline could be induced either by the corporate sector demanding less credit -- because fewer investments are undertaken -or by the banks' reluctance to lend. By contrast, if the decline in (the dynamics of) bank loans is coupled with a widening of the spread between bank lending rates and the rates prevailing on analogous non-bank debt market instruments, then it can be argued that an 
adverse shift in the banks' supply of loans is curtailing credit. In fact, such a situation is consistent with only two possibilities: either supply has declined whereas demand has not, or supply has declined more than demand.

Furthermore, we follow the widely held recommendation (Bernanke and Gertler, 1995; Hubbard, 1995) to split the credit channel impact into two separate components: the balance sheet effect and the lending channel effect.

The balance sheet effect emphasizes the potential depressing impact of the monetary squeeze on borrowers' assets and profits, by affecting variables such as borrowers' net worth, cash flow and liquid assets, which increases the risk premium. The increase in the level of interest rates triggered by the monetary squeeze raises corporate risks because it reduces both business profits and the value of assets that firms have posted as collateral. This will generally increase the wedge between the interest rates at which corporates can borrow and the yields on otherwise analogous risk-free assets.

By contrast, the bank lending channel effect focuses on the retrenchment in the supply of loans by depository institutions in the wake of the monetary restriction. Specifically, the chain of actions runs as follows. The monetary squeeze raises the level of interest rates even for risk-free assets such as T-bills and Government bonds. In general, banks cannot increase deposit rates by as much since they have to build required reserves which either bear no-remuneration or offer a below-market yield. This means that banks suffer a deposit drain as investors reshuffle their portfolios away from deposits and towards assets with more attractive yields. Banks are not indifferent between making loans to the private sector and holding Government securities -- i.e. Government securities provide a cost efficient way to carry a secondary liquidity cushion, and banks 
may be unwilling to deplete their holding of such securities below some threshold. Accordingly, following the deposit drain, they will probably enact a restriction in their loan supply. If all firms were indifferent between borrowing at banks and issuing debt on the market, this would not imply that bank lending rates should increase more than corporate debt market rates. In reality, however, we know that the majority of businesses do not issue debt on the market. Consequently, after the monetary tightening we can expect that the wedge between bank lending rates and corporate debt market rates may also increase. ${ }^{3}$

Finally, we rely on previous studies built on the hypothesis that credit channel effects are likely to be most important for those firms which, being unable to issue debt on the market, could be classified as bank-dependent borrowers. This suggests that the credit channel is likely to particularly penalize the small and medium-sized enterprises (SMEs), ${ }^{4}$ most of which are de facto bank-dependent borrowers. ${ }^{5}$ An additional reason for SMEs being disproportionately affected by credit channel effects derives from the possibility that the monetary squeeze triggers a flight to quality in bank lending. More specifically, banks may respond to the monetary restriction, not only restraining credit generally, but also by adopting more stringent lending policies vis-à-vis customers that

3 A similar impact could be induced by the introduction of stricter regulations on banks: e.g. the imposition of higher capital adequacy ratios (Bernanke and Lown (1992)).

4 Gertler and Gilchrist (1994) show evidence consistent with this hypothesis.

5 In the first place. SMEs are too small to justify the fixed costs entailed by listing securities. In addition, even when they have the intention of issuing debt on the market, they will most likely refrain from doing so. Because of the low liquidity of their debt. investors would ask for very high yields, thus making issuance unattractive. 